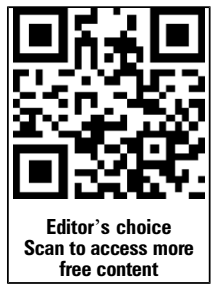

free content
${ }^{1}$ Emergency Department, Austin Hospital, Heidelberg, Victoria, Australia

${ }^{2}$ Department of Medicine, University of Melbourne, Melbourne, Victoria, Australia

\section{Correspondence to}

Professor David McD Taylor, Emergency Department, Austin Hospital, Studley Road, Heidelberg VIC 3084

Australia;

David.Taylor@austin.org.au

Received 13 September 2015 Revised 14 February 2016 Accepted 16 February 2016 Published Online First 7 March 2016
CrossMark

To cite: Taylor DMD, Grover Johnson 0 , Lee $\mathrm{M}$, et al. Emerg Med J 2016;33: 453-457.

\title{
The effect of provision of pain management advice on patient satisfaction with their pain management: a pilot, randomised, controlled trial (pain advice trial)
}

\author{
David McD Taylor, ${ }^{1,2}$ Olivia Grover Johnson, ${ }^{2}$ Marina Lee, ${ }^{2}$ Juen Li Ding, ${ }^{2}$ \\ Aadith Ashok ${ }^{2}$
}

\begin{abstract}
Objective We aimed to provide pain advice ('The treatment of pain is very important and be sure to tell the staff when you have pain') as an intervention and evaluate its effect upon patient satisfaction. The purpose of this pilot trial was to ensure the design and methods of a future trial are sound, practicable and feasible. Method We undertook a pilot, randomised, controlled, clinical intervention trial in a single ED. The control arm received standard care. The intervention arm received standard care plus pain advice from an independent investigator. All patients and treating ED staff were blinded to patient enrolment. Patient satisfaction with their pain management (six-point ordinal scale) was measured $48 \mathrm{~h}$ post-ED discharge, by a blinded researcher. The primary outcome was satisfaction with pain management.
\end{abstract}

Results Of the 280 and 275 patients randomised to the control and intervention arms, respectively, 196 and 215 had complete data, respectively. $77.6 \%$ (152/196) and $88.8 \%$ (191/215) of patients reported being provided with pain advice, respectively (difference 11.3\% $(95 \% \mathrm{Cl} 3.6$ to 19.0)). The intervention was associated with absolute and relative increases in patient satisfaction of $6.3 \%$ and $14.2 \%$, respectively. $91.3 \%$ (179/196) and $76.3 \%$ (164/215) of patients who were/ were not very satisfied reported having received 'pain advice' (difference $15.0 \%$ (95\% Cl 7.6 to 22.5)).

Conclusions The intervention to provide pain advice resulted in a non-significant increase in patient satisfaction. A larger multicentre trial is feasible and is recommended to further explore the effects of provision of pain advice.

Trial registration number ACTRN12615000097549.

\section{INTRODUCTION}

Pain is the most common reason for presenting to the ED, accounting for $78 \%$ of visits. ${ }^{1}$ Despite this, the inadequate use of analgesics, in the face of valid indications, is a widely recognised problem affecting ED patients. ${ }^{2}$ However, analgesia administration represents only one, although important, aspect of good pain management. Arguably, the ultimate goal of pain management is a high level of patient satisfaction with that management. Indeed, patient satisfaction is associated with increased compliance, decreased malpractice litigation, less usage of medical services and a greater willingness to return to the healthcare provider. ${ }^{3-6}$

\section{Key messages}

What is already known on this subject?

- Good patient satisfaction with their management is associated with a range of desirable outcomes including increased compliance and follow-up.

- Initiatives aiming to improve pain management usually employ surrogate endpoints that do not relate directly to patient satisfaction, for example, time-to-analgesia.

- The provision of 'pain advice' ('The treatment of pain is very important and be sure to tell the staff when you have pain') is associated with high levels of patient satisfaction with their pain management.

What might this study add?

- This pilot, randomised, blinded trial employed an intervention of 'pain advice' which resulted in a non-significant increase in patient satisfaction.

- The effect size of this intervention will inform the design of larger studies.

- There is a significant positive association between the perceived frequency of pain score measurement and patient satisfaction.

Initiatives attempting to improve pain management in the ED have been undertaken including staff training, ${ }^{7}$ time-to-analgesia key performance indicators, ${ }^{8}$ nurse-initiated analgesia ${ }^{9}$ and mandatory recording of triage pain scores. ${ }^{10}$ However, the endpoints of many initiatives do not relate to patient satisfaction, for example, while nurse-initiated times-to-analgesia may be short, the effectiveness of that analgesia and hence patient satisfaction may not be optimal. ${ }^{11}$

Recent studies have reported that patients are significantly more likely to be very satisfied with their pain management if they are provided with 'pain advice', that is, being told by the ED staff that 'The treatment of pain is very important and be sure to tell the staff when you have pain'. ${ }^{11-13}$ While it might be reasonable to expect that ED staff would routinely provide such pain advice, this does not always happen. ${ }^{13}$ Given these findings, we hypothesise that ensuring pain advice is provided would result in increased patient satisfaction. 
This pilot trial was an essential preliminary to a definitive randomised controlled trial assessing the effectiveness of the provision of pain advice, in addition to standard care. The purpose of the pilot was to ensure the design and methods of that future trial are sound, practicable and feasible. The aims were: (1) to test the feasibility, practicality and acceptability of the study design and protocol; (2) to resolve practical issues for the conduct of the future trial such as the reproducibility of the outcome measures, and recruitment and attrition rates and (3) to inform the sample size calculation for the future trial.

\section{METHODS}

\section{Trial design}

We undertook a pilot, randomised, controlled, clinical intervention trial in the ED of a tertiary referral hospital between February and May 2015. The ED has a mixed (adult/paediatric) annual census of approximately 77000 patients. The trial was approved by the institution's Human Research Ethics Committee and registered on the Australian New Zealand Clinical Trials Registry prior to data collection (ACTRN12615000097549).

\section{Participants}

A convenience sample of eligible patients was enrolled during periods when a study investigator was available (mainly 09:00-22:00, Monday-Friday). Patients were eligible for inclusion if they were aged 18 years or more and had moderatesevere pain (triage pain score $\geq 4$ on a verbal numerical rating scale $\left.0-10^{14}\right)$. They were excluded if they were triage category 1 (to be seen immediately upon presentation), had suspected cardiac chest pain, were too ill to approach (determined by the ED staff), were unable to communicate adequately (significant disability, severe illness and poor English), had no means for follow-up (eg, no telephone) or if they declined participation in the follow-up interview.

\section{Participant enrolment}

Consecutive patients meeting the study entrance criteria were identified by an investigator who then prospectively collected data while the patient was in the ED. These data included demographics (age, sex and ethnicity), triage pain score, triage category, ${ }^{15}$ indication for analgesia and nature of the analgesia administered (none, simple (paracetamol \pm codeine, nonsteroidal anti-inflammatory drugs), oral or parenteral opioids).

\section{Randomisation}

A randomisation list of study ID numbers (from 1 to 700 ) was prepared by the principal investigator prior to study commencement. Each study ID number was then randomly allocated to one of the two study arms using a computer programme. No randomisation restrictions were used. An investigator in the ED held the randomisation list. When a patient meeting the study entrance criteria was identified, the investigator assigned them to the next available study ID number on the list and hence their study arm allocation. The investigator then provided the intervention to patients assigned to the intervention arm.

\section{Intervention}

Patients randomised to the control arm received standard care only with no additional care provided. These patients were not approached by the investigators while they were in the ED. Patients randomised to the intervention arm received standard care plus pain advice, from an investigator and on a single occasion only, shortly after they were admitted to the ED. The pain advice comprised a single sentence: 'The ED staff consider pain treatment is very important so be sure to tell the ED nurse when you have pain'. There was no other intervention.

\section{Blinding}

Prior to study commencement, the ED staff were told that a pain study, examining how staff interact with their patients, would be undertaken. They were advised that they would not need to do anything as part of the study and that the investigators would collect all data. They were not advised of the study hypothesis in order to avoid any potential observer effects, that is, they may have deviated from standard care and/or there may have been a 'learning effect'. All investigator interactions with the patients occurred at times when the ED staff were not in attendance, for the same reasons.

During their ED stay, patients (in both arms) were neither advised that they were part of a research study nor that they would be followed up after discharge from the ED. This technique has been used previously in order to avoid the Hawthorne effect impacting upon the outcome measures. ${ }^{13}$ Hence, both patients and ED staff were blinded to enrolment and the provision of pain advice to the intervention group.

\section{Follow-up}

An investigator who did not interact with the patients in the ED and who was, therefore, blinded to the patients' randomisation status, collected follow-up data $48 \mathrm{~h}$ post discharge (or as soon as possible thereafter). This was either by telephone or in person if the patient was admitted to a hospital ward. The patients' telephone numbers were extracted from their medical record. A minimum of three calls were made before any patient was deemed as uncontactable.

At follow-up, the project was briefly described and the patients were invited to answer three questions:

1. 'During your stay[in the ED], was it made clear to you that the staff consider treatment of pain very important and that you should be sure to tell them when you have pain?'

This question was adapted from the American Pain Society Patient Outcomes Questionnaire (APS-POQ) for the ED setting. It has been used previously in both interview and patient selfreport formats. ${ }^{13} 16$

2. 'During your stay, how frequently were you asked to score your pain?'

A four-item ordinal scale provided patients with response options: not at all, infrequently, frequently and very frequently. This scale was trialled on patients prior to the commencement of data collection. It sought the patients' perception of the frequency of pain scoring.

3. 'How satisfied or dissatisfied are you with the results of your pain treatment[in the ED], overall?'

Satisfaction was measured using a six-point ordinal scale (very dissatisfied-very satisfied). This question is adapted from the APS-POQ for the ED setting. ${ }^{16}$ The adapted question has been used in a number of other studies. ${ }^{11-13}$

\section{Study outcomes}

The primary study outcome was the level of patient satisfaction with their pain management. Specifically, the outcome used for analyses was the proportion of patients who were 'very satisfied' with their pain management. This represents the highest level of patient satisfaction. Anything short of this would suggest that pain management was lacking and could have been improved. The secondary outcomes were the proportions of patients who reported having been given pain advice during their ED stay 
and the perceived frequency of pain score measurement. The actual frequency of pain score measurement was not known as it is often under-recorded in the medical record.

\section{Sample size}

As a pilot study, the main purpose was to determine the 'effect size' of the pain advice intervention. Given this, the study was not powered to demonstrate a statistically significant change in patient satisfaction. However, a recent multicentre clinical trial $^{13}$ indicated that approximately $80 \%$ of patients recall being provided with pain advice as part of standard care. We expected that at least $90 \%$ of patients in the intervention arm of this pilot would recall having received pain advice. With a sample size of 400 patients, the pilot had a power of 0.76 to demonstrate this difference (two-sided, level of significance 0.05). Demonstration of this difference would indicate that the intervention had been successfully introduced. It was considered that 200 patients in each of the study arms (total 400) would be adequate for this purpose.

\section{Statistical methods}

The data are reported descriptively as absolute numbers and proportions of patients within relevant groups. Differences in proportions, with 95\% CIs, are reported for group comparisons. All data were analysed with SPSS for Windows statistical software (V.22.0, SPSS, Chicago, Illinois, USA).

\section{RESULTS}

\section{Participant flow}

Of 588 patients screened for enrolment, 33 did not meet the study entrance criteria and were excluded (figure 1). A total of $144(24.5 \%)$ patients were excluded after randomisation, almost all because they could not be contacted. Few declined participation in the follow-up survey.

\section{Baseline data}

Significantly, more patients in the standard care arm were excluded than the intervention arm $(30.0 \%$ vs $21.8 \%$, difference $8.2 \%$ (95\% CI 0.6 to 15.8$)$ ). Patients excluded in the two arms did not differ significantly in the baseline characteristics of age, gender, ethnicity, triage category or pain score, indication for analgesia, receipt of nurse-initiated analgesia or the nature of analgesia administered. However, more patients in the standard care arm received analgesia of some sort (80.6\% vs $70.6 \%)$.

Complete data were obtained from 196 and 215 patients who were randomised to the standard care and intervention arms, respectively. The groups did not differ in baseline characteristics (table 1).

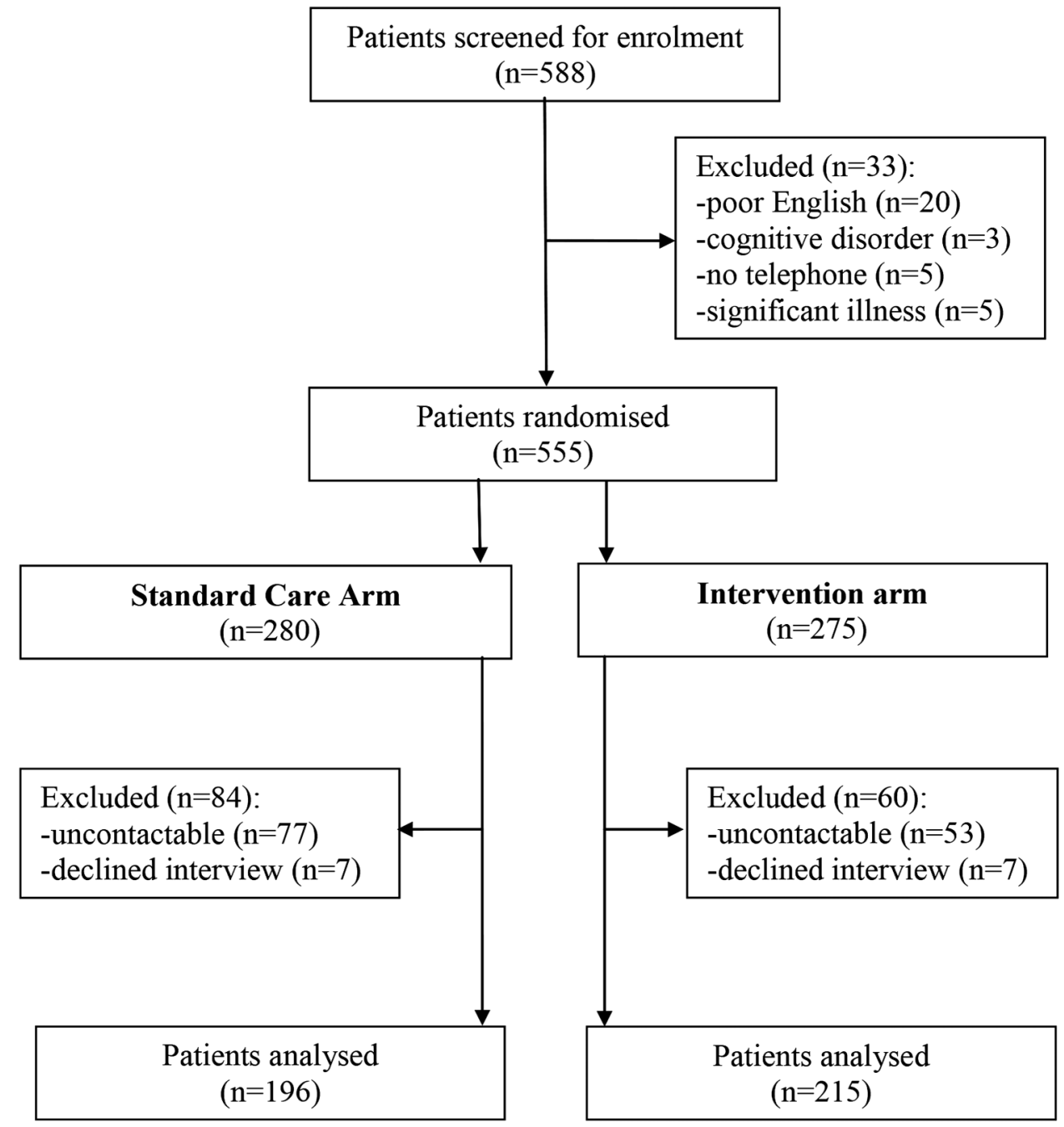

Figure 1 Patient flow through the study. 
Table 1 Baseline characteristics of the two study arms

\begin{tabular}{|c|c|c|}
\hline Variable & $\begin{array}{l}\text { Standard care arm, } \mathrm{n}=196 \\
\mathrm{n}(\%)\end{array}$ & $\begin{array}{l}\text { Intervention arm, } \mathrm{n}=215 \\
\mathrm{n}(\%)\end{array}$ \\
\hline \multicolumn{3}{|l|}{ Age, years } \\
\hline $18-29$ & $52(26.5)$ & $44(20.5)$ \\
\hline $30-49$ & $64(32.7)$ & $72(33.5)$ \\
\hline $50-69$ & $53(27.0)$ & $62(28.8)$ \\
\hline$>70$ & $27(13.8)$ & 37 (17.2) \\
\hline Male & $96(49.0)$ & 89 (41.4) \\
\hline \multicolumn{3}{|l|}{ Ethnicity } \\
\hline Aust/NZ/Brit* & $150(76.5)$ & $158(73.5)$ \\
\hline Italian & $6(3.1)$ & $12(5.6)$ \\
\hline Greek & $4(2.0)$ & $6(2.8)$ \\
\hline Other European & $6(3.1)$ & $6(2.8)$ \\
\hline Asian & $7(3.6)$ & $11(5.1)$ \\
\hline Other & $23(11.7)$ & $22(10.2)$ \\
\hline \multicolumn{3}{|l|}{ Triage pain score } \\
\hline 4 & 39 (19.9) & 46 (21.4) \\
\hline 5 & $49(25.0)$ & $54(25.1)$ \\
\hline 6 & 35 (17.9) & 40 (18.6) \\
\hline 7 & 27 (13.8) & 33 (15.3) \\
\hline 8 & 35 (17.9) & $24(11.2)$ \\
\hline 9 & $3(1.5)$ & $13(6.0)$ \\
\hline 10 & $8(4.1)$ & $5(2.3)$ \\
\hline \multicolumn{3}{|l|}{ Triage category } \\
\hline 2 & $19(9.7)$ & $16(7.4)$ \\
\hline 3 & $104(53.1)$ & $134(62.3)$ \\
\hline 4 & $69(35.2)$ & 60 (27.9) \\
\hline 5 & $4(2.0)$ & $5(2.3)$ \\
\hline \multicolumn{3}{|l|}{ Indication } \\
\hline Trauma & $28(14.4)$ & 29 (13.5) \\
\hline Abdominal pain & 54 (27.6) & 70 (32.6) \\
\hline Headache & $10(5.1)$ & $13(6.0)$ \\
\hline Chest pain & $9(4.6)$ & $12(5.6)$ \\
\hline Other & $95(48.5)$ & $91(42.3)$ \\
\hline \multicolumn{3}{|l|}{ Analgesia given } \\
\hline Nurse initiated & $85(43.4)$ & $104(48.4)$ \\
\hline Any analgesia & 139 (70.9) & $151(70.2)$ \\
\hline Simple analgesia & 107 (54.6) & $117(54.4)$ \\
\hline Oral opioid & $83(42.3)$ & 89 (41.4) \\
\hline Parenteral opioid & $26(13.3)$ & 31 (14.4) \\
\hline
\end{tabular}

\section{Outcomes}

Overall, $196(47.7 \%)$ patients were very satisfied with their pain management. A greater proportion of patients in the intervention arm were very satisfied (table 2). Although the groups did not differ statistically, the absolute difference was $6.3 \%$ and the relative difference was $14.2 \%$. The majority of patients in both groups reported having received pain advice in the ED. However, significantly more patients in the intervention group (almost 90\%) reported having received pain advice. The groups did not differ significantly in their perceptions of how frequently pain scores were collected.

Among all patients, there was a significant association between the provision of pain advice and patient satisfaction with their pain management (table 3). Almost all (>90\%) patients who were very satisfied with their pain management reported having received pain advice. Similarly, there was a significant association between the perceived frequency of pain score measurement and patient satisfaction. Patients who were very satisfied reported more frequent pain score measurement.
Table 2 Outcome measures of the two study arms

\begin{tabular}{|c|c|c|c|}
\hline Variable & $\begin{array}{l}\text { Standard } \\
\text { care arm } \\
\mathrm{n}=196\end{array}$ & $\begin{array}{l}\text { Intervention } \\
\text { arm } \\
n=215\end{array}$ & $\begin{array}{l}\text { Difference in } \\
\text { proportions \% } \\
\text { (95\% Cls) }\end{array}$ \\
\hline $\begin{array}{l}\text { Very satisfied with } \\
\text { pain management }\end{array}$ & $87(44.4)$ & $109(50.7)$ & $6.3(-3.8$ to 16.4$)$ \\
\hline Pain advice received & $152(77.6)$ & $191(88.8)$ & 11.3 (3.6 to 19.0 ) \\
\hline $\begin{array}{l}\text { Pain scoring perceived } \\
\text { as frequent or very } \\
\text { frequent }\end{array}$ & $95(48.5)$ & $111(51.6)$ & 3.1 ( -7.0 to 13.3$)$ \\
\hline
\end{tabular}

\section{DISCUSSION}

The provision of pain advice was associated with non-significant increases $(6.3 \%$ absolute and $14.2 \%$ relative) in the proportion of patients who were very satisfied with their pain management. We believe that an absolute increase of $5 \%$ would be clinically significant. Importantly, these increases were achieved with a very simple and quick interaction with the intervention arm patients. The simplicity of the intervention and its effect size indicate its potential importance in the ED setting. If the effect size $(6.3 \%)$ were observed in a definitive trial, a sample size of approximately 2000 patients would be needed. Assuming a recruitment rate similar to this pilot, this sample size could be achieved across five EDs in 4 months.

The intervention arm of this study had a significantly greater proportion of patients who reported the receipt of pain advice. This indicates the feasibility of providing the intervention in this setting. It is notable that a large proportion of patients $(77.6 \%)$ in the standard care arm reported having received pain advice. This is consistent with earlier studies ${ }^{11-13}$ and suggests that, at least in this regard, pain management is likely to be reasonable. For many clinical trials the intervention is entirely absent in the control arm, for example, an experimental drug versus placebo. In this pilot, the provision of pain advice clearly comprised part of standard care and the intervention arm could only provide a relative increase in the proportion of patients who received it. The finding that not all patients in the intervention arm reported the receipt of pain advice is not surprising as many factors are likely to have introduced recall bias (eg, pain, anxiety, analgesia and the busy unfamiliar ED environment).

The significant association between the provision of pain advice and patient satisfaction is consistent with other

Table 3 Variables associated with patient satisfaction with their pain management (patients in both arms pooled)

\begin{tabular}{|c|c|c|c|}
\hline Variable & $\begin{array}{l}\text { Not very } \\
\text { satisfied } \\
n=215\end{array}$ & $\begin{array}{l}\text { Very satisfied } \\
n=196 \\
\text { n (\%) }\end{array}$ & $\begin{array}{l}\text { Difference in } \\
\text { proportions \% } \\
\text { (95\% Cls) }\end{array}$ \\
\hline Pain advice received & $164(76.3)$ & $179(91.3)$ & 15.0 (7.6 to 22.5$)$ \\
\hline $\begin{array}{l}\text { Pain scoring } \\
\text { perceived as } \\
\text { frequent or very } \\
\text { frequent }\end{array}$ & $93(43.2)$ & $113(57.6)$ & 14.4 (4.3 to 24.5$)$ \\
\hline
\end{tabular}


reports. ${ }^{11-13}$ There is now mounting evidence of the importance of pain advice provision in the ED setting. This study has demonstrated that this does occur already for a large proportion of patients. There is, however, the opportunity to increase this proportion.

The significant association between the perceived frequency of pain score measurement and patient satisfaction has not been reported previously. The reasons for this association are not known. Frequent measurement may be perceived by patients as a real concern by the ED staff about their pain and well-being generally. However, many confounding variables are likely to impact upon this association, for example, the level of pain itself and the nature of the analgesia administered. Further research is recommended to further explore this association.

\section{Limitations}

As a pilot, it was designed to determine the effect size of the intervention and was not powered to demonstrate statistically significant differences in satisfaction between the two arms.

The intervention involved the provision of pain advice on only a single occasion. This was deliberate as the effect size of the smallest possible intervention was sought. It is not known what the effect of repeating this advice would be although, intuitively, it would likely be larger. Also, the pain advice provided as part of the intervention was provided by an independent investigator and not by the ED staff providing patient care. It is not known if this would have been more or less effective than the intervention being provided by the staff. Although conjecture, the provision of pain advice by the staff may be more effective if it also helps to concentrate their attention on the patients' pain and changes their pain management accordingly.

Many patients were lost to follow-up. The blinding of patients during their ED stay precluded the opportunity for the investigators to check the patients' contact details directly. Reliance was placed on those in the medical record which, anecdotally, can be inaccurate or out of date. The convenience sampling and the differences between the study arms (more patients lost and more having received analgesia in the standard care arm) may have introduced selection bias. However, very few patients declined participation in the follow-up interview and it is unlikely that selection bias substantially affected the results.

The satisfaction scale employed is a crude tool to measure patient satisfaction and is subject to a wide range of confounding variables and recall bias. However, the proportion of very satisfied patients $(47.7 \%)$ is within the range $(39.9 \%-48.5 \%)$ reported by other ED studies that employed this scale. ${ }^{11-13}$ Similarly, the question to determine if pain advice had been provided, although previously validated, is also subject to recall bias. However, the proportion of all patients who reported having received this advice $(83.5 \%)$ is within the range $(79.0 \%-$ $85.6 \%)$ reported by other ED studies. ${ }^{11-13}$ The similarity of these proportions suggests that both tools are likely to perform adequately.

\section{Generalisability}

As a single-centre study, the external validity of the findings is limited. The results suggest that the study ED manages pain reasonably well with just less than one-half of standard care patients being very satisfied and with three quarters receiving pain advice. As EDs that manage pain less well would have a greater scope to improve these management metrics, it is possible that the pain advice intervention could result in larger effect sizes.

\section{CONCLUSION}

This pilot study confirms the association between provision of pain advice and patient satisfaction with their pain management. The intervention, provision of pain advice on a single occasion, resulted in a non-significant increase in the proportion of patients who were very satisfied, compared with patients who received standard care alone. The intervention was easily and quickly administered, appeared acceptable to patients and resulted in a clinically significant increase in patient satisfaction. It is recommended that a larger multicentre trial is undertaken to further explore the effects of provision of pain advice. The effect size and rates of loss to follow-up observed in this pilot should be used to inform the sample size of the larger trial.

Contributors All authors contributed to development of the study protocol. DMT obtained ethics committee approval. OGJ, ML, JLD and AA collected all data. DMT analysed the data and prepared the first manuscript draft. All authors contributed to manuscript revision and all approved of the final manuscript.

Competing interests None declared.

Ethics approval Austin Health Human Research Ethics Committee.

Provenance and peer review Not commissioned; externally peer reviewed.

\section{REFERENCES}

1 Cordell WH, Keene KK, Giles BK, et al. The high prevalence of pain in emergency medical care. Am J Emerg Med 2002;20:165-9.

2 Fosnocht DE, Swanson ER, Barton ED. Changing attitudes about pain and pain control in emergency medicine. Emerg Med Clin North America 2005;23:297-306.

3 Ley P. Satisfaction, compliance and communication. Br J Clin Psych 1982;21:241-54.

4 Di Matteo MR, DiNicola DD. Achieving patient compliance: the psychology of the medical practitioner's role. New York: Pergamon Press, 1982.

5 Sun BC, Adams JG, Burstin HR. Validating a model of patient satisfaction with emergency care. Ann Emerg Med 2001;38:527-32.

6 Weiss GL. Patient satisfaction with primary medical care evaluation of sociodemographic and predispositional factors. Med Care 1988;26:383-92.

7 Decosterd I, Hugli 0 , Tamchès $E$, et al. Oligoanalgesia in the emergency department: short-term beneficial effects of an education program on acute pain. Ann Emerg Med 2007;50:462-71.

8 Schull MJ, Guttmann A, Leaver CA, et al. Prioritizing performance measurement for emergency department care: consensus on evidence-based quality of care indicators. Can J Emerg Med 2011;13:300-9.

9 Taylor SE, Taylor DM, Jao K, et al. Nurse-initiated analgesia pathway for paediatric patients in the emergency department: a clinical intervention trial. Emerg Med Australas 2013;25:316-23.

10 Vazirani J, Knott JC. Mandatory pain scoring at triage reduces time to analgesia. Ann Emerg Med 2012;59:134-8.

11 Jao K, McD Taylor D, Taylor SE, et al. Simple clinical targets associated with a high level of patient satisfaction with their pain management. Emerg Med Australas 2011;23:195-201.

12 Shill J, Taylor DM, Ngui B, et al. Factors associated with high levels of patient satisfaction with pain management. Acad Emerg Med 2012;19:1212-15.

13 Taylor DMcD, Fatovich D, Finucci D, et al. Best-practice pain management in the ED: a multi-centre, cluster-randomised, controlled, clinical intervention trial. Emerg Med Australas 2015;27:549-57.

14 Bijur PE, Latimer CT, Gallagher EJ. Validation of a verbally administered numerical rating scale of acute pain for use in the emergency department. Acad Emerg Med 2003:10:390-2.

15 The Australasian College for Emergency Medicine. Policy Document: The Australasian Triage Scale. http://enw.org/AustralianTriageScales\%20Policy.pdf (accessed 8 Sep 2015).

16 [No authors listed]. Quality improvement guidelines for the treatment of acute pain and cancer pain. American Pain Society Quality of Care Committee. JAMA 1995;274:1874-80. 